Article

\title{
Evaluation and Observation of Autogenous Healing Ability of Bond Cracks along Rebar
}

\section{Choonghyun Kang ${ }^{1} *$ and Minoru Kunieda ${ }^{2}$}

1 School of Architecture \& Civil Engineering, Kyungpook National University, 80, Daehak-ro Buk-gu, Daegu 702-701, Korea

2 Department of Civil Engineering, Faculty of Engineering, Gifu University, 1-1 Yanagido, Gifu 501-1193, Japan; E-Mail: kunieda@gifu-u.ac.jp

* Author to whom correspondence should be addressed; E-Mail: kangcivil@ gmail.com; Tel.: +82-10-6357-8142.

Received: 10 January 2014; in revised form: 22 March 2014 / Accepted: 11 April 2014 / Published: 17 April 2014

\begin{abstract}
Micro cracks occurring in concrete around tensile rebar is well known latent damage phenomenon. These micro cracks develop, and can be detected after reaching the surface of the concrete. Detection of these cracks before they are fully formed is preferable, but observing the whole crack structure is difficult. Another problem is repairing micro cracks under the concrete surface. The autogenous ability of bond cracks along rebar was evaluated using the air permeability test. Air permeability coefficients were measured before and after tensile loading, and experimental air permeability coefficients became larger near cracks along rebar as a result of tensile loading. Recuring for 28 days after tensile loading made the air permeability coefficients smaller, but this restriction only occurred during water recuring. Observation of crack patterns helped the understanding of change in the air permeability coefficients. Several small cracks along rebar were observed after tensile loading, and most cracks along rebar were not found after water recuring. On the other hand, the crack pattern did not change after air recuring. These results indicate that bond cracks along rebar can be closed by autogenous healing, and cause the air permeability coefficients.
\end{abstract}

Keywords: autogenous healing; bond cracks; air permeability test; crack pattern; ink injection 


\section{Introduction}

Bond cracks are a form of damage that can occur in concrete around rebar, which were reported by Goto [1]. Several mechanisms of bond behavior have been investigated, such as chemical bonding, frictional bonding, mechanical bonding as a result of ribs, etc. Micro cracks were induced by these bonds between rebar and concrete, and it develops itself by several reasons such as relation with aggregate, crack bridging or post peak reaction [2-4]. The bond cracks may accelerate the penetration of substances such as water and gas, and it also makes the rebar corrosion area wider. These micro cracks should be repaired before significant damage develops. However, there is no way to detect these micro cracks under a thick concrete cover. In addition, the repair method has not been determined.

Autogenous healing of cementitious composite was well known phenomenon of automatic crack recovery. Focus was placed on this phenomenon as a repair method, but the applicability of autogenous healing is limited because several required circumstances must be satisfied for autogenous healing to occur. These circumstances include the mix proportion of cementitious materials, presence of water, crack width, water pressure, and stability of the crack, etc. [5-7]. Most past researches have concerned autogenous healing ability of bending cracks. As mentioned above, recovery of bond cracks along rebar is one of the applications, because these cracks are very fine and difficult to repair by ordinary repair techniques such as a crack injection.

In this study, autogenous healing was investigated as a recovery mechanism for bond cracks along rebar. Autogenous healing is a viable method because cracks along rebar are widely distribute, but small. The method of detection was the air permeability test, which is a non-destructive method using surface measurements. The measured air permeability coefficient was used to measure the degree of damage caused by the bond cracks, and to evaluate the effect of autogenous healing. In addition, observation of crack patterns using ink injection visually showed the amount of area recovered by the autogenous healing process.

\section{Experimental Investigation}

\subsection{Specimen}

Figure 1 shows the shape of the concrete specimen. Rectangle specimens with dimensions of $150 \mathrm{~mm} \times 150 \mathrm{~mm} \times 500 \mathrm{~mm}$ were prepared. The size of the cross sections was considered in measuring the air permeability. D22 rebar was embedded in the center of each specimen to induce tensile force. Notches having a depth of $20 \mathrm{~mm}$ and a thickness of $3 \mathrm{~mm}$ were made at both sides and center of the specimen.

Normal concrete and fly ash concrete were used in this study. Termkhajornkit et al., reported that $\mathrm{C}-\mathrm{S}-\mathrm{H}$ gel produced by the pozzolanic reaction of fly ash acted to seal micro cracks [8,9] The mix proportions are in Table 1. The water to cement ratio (W/C) was $45 \%$ in all mixes. Ordinary Portland cement with a density of $3.15 \mathrm{~g} \cdot \mathrm{cm}^{-3}$, sand with a surface-dry density of $2.51 \mathrm{~g} \cdot \mathrm{cm}^{-3}$, a coarse aggregate with a surface-dry density of $2.58 \mathrm{~g} \cdot \mathrm{cm}^{-3}$ and with a maximum size of $20 \mathrm{~mm}$ were used. Fly ash (Type II of JIS A 6210, Techno Chubu Company, Nagoya, Japan), which has a density of $2.38 \mathrm{~g} \cdot \mathrm{cm}^{-3}$, was also used. 
Figure 1. Shape of specimen.
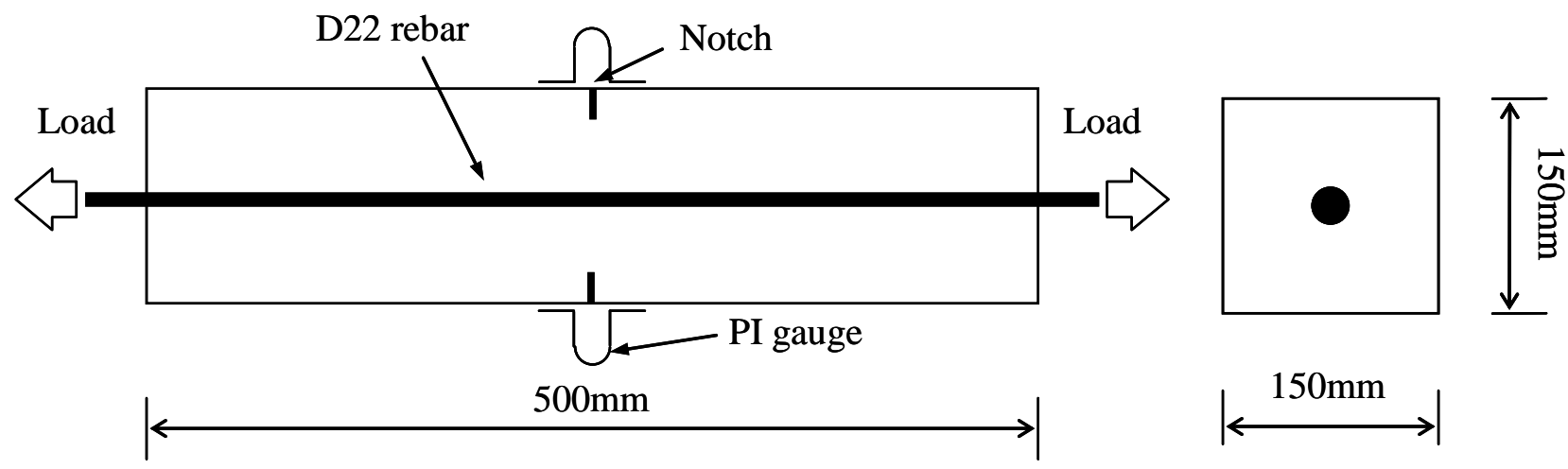

Table 1. Mix proportions.

\begin{tabular}{|c|c|c|c|c|c|c|c|c|}
\hline \multirow{2}{*}{ Case } & \multirow{2}{*}{$\mathrm{W} / \mathrm{C}(\%)$} & \multirow{2}{*}{$\mathrm{s} / \mathrm{a}(\%)$} & \multicolumn{5}{|c|}{ Unit Content $\left(\mathrm{kg} \cdot \mathrm{m}^{-3}\right)$} & \multirow{2}{*}{$\frac{\text { Admixture }\left(\mathrm{cc}^{\prime} \mathrm{m}^{-3}\right)}{\text { AEA }^{\dagger}}$} \\
\hline & & & Water & Cement & Sand & Gravel & Fly Ash & \\
\hline Normal Concrete & 45 & 47 & 170 & 377 & 780 & 903 & - & 0.97 \\
\hline Fly ash Concrete & 45 & 47 & 170 & 377 & 716 & 903 & 58 & 0.97 \\
\hline
\end{tabular}

$\mathrm{AEA}^{\dagger}$ : Air entraining agent.

\subsection{Tensile Loading}

Tensile loading was performed to induce bond cracks along rebar. The tensile force was applied by the rebar embedded in the center of the specimen. Crack opening displacement, which was measured by two PI gauges attached to the specimen surface over the notches, was monitored during the loading tests. Figure 2 shows the experimental setup and load-crack opening displacement relationship. Several pretests were performed to determine the unloading level $(0.5,1.0$ and $2.0 \mathrm{~mm})$. Consequently, an unloading point of $1.0 \mathrm{~mm}$ was applied in this study.

Figure 2. Experimental setup and load-displacement relationship.
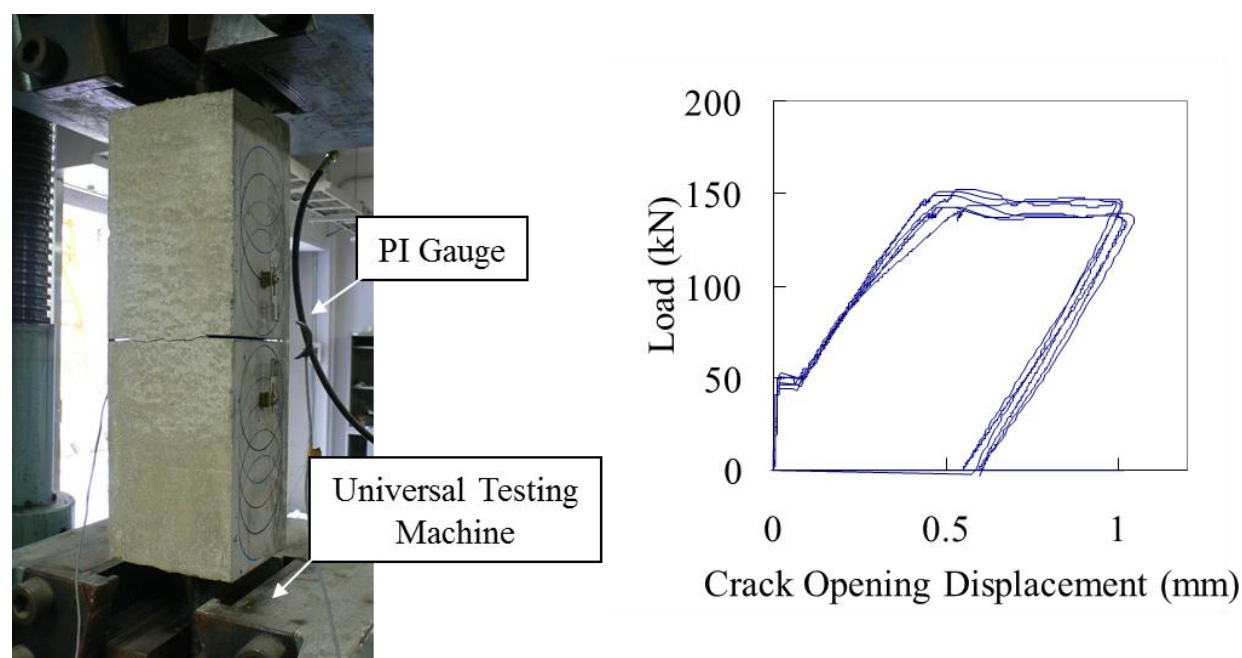


\subsection{Air Permeability Test}

A sensitive index needed to be selected to evaluated the degree of damage due to bond cracks and the recovery effect of the autogenous healing phenomenon. Air permeability tests were conducted using the Torrent Permeability Test (TPT), proposed by Torrent [10]. As shown in Figure 3, the device consisted of chamber, vacuum pump, pressure sensor, and logger. To prevent spurious ingress of air along the skin, there are two chambers: an outer chamber and an inner chamber. After the desired level of vacuum was attained, the pump only acted on the outer chamber. Meanwhile, the logger recorded the history of change in the inner chamber. A spurious ingress from the concrete surface is evacuated by outer chamber, and uniaxial air flow can be measured through the pressure of both chambers, as shown in Figure 4. After twelve minutes of data logging, the air permeability coefficient was calculated using Equation (1) based on the theoretical model:

$$
k=4\left(\frac{V_{\mathrm{c}}\left(\mathrm{d} P_{1} / \mathrm{d} t\right)}{A\left(P_{\mathrm{a}}^{2}-P_{I}^{2}\right)}\right)^{2} \frac{\mu P_{\mathrm{a}}}{\varepsilon} \int_{t_{0}}^{t}\left[1-\left(\frac{P_{\mathrm{I}}}{P_{\mathrm{a}}}\right)^{2}\right] \mathrm{d} t
$$

Here $k$ is the air permeability coefficient $\left(\mathrm{m}^{2}\right), V_{\mathrm{c}}$ is the volume of the inner chamber $\left(\mathrm{m}^{3}\right), A$ is the cross-sectional area of the inner chamber $\left(\mathrm{m}^{2}\right), P_{1}$ is the pressure in inner chamber $\left(\mathrm{N} / \mathrm{m}^{2}\right), P_{\mathrm{a}}$ is the atmospheric pressure $\left(\mathrm{N} / \mathrm{m}^{2}\right), \mu$ is the dynamic viscosity of air $\left(\mathrm{Ns} / \mathrm{m}^{2}\right)$, and $\varepsilon$ is the empty porosity of the concrete.

Figure 3. Torrent Permeability Tester.

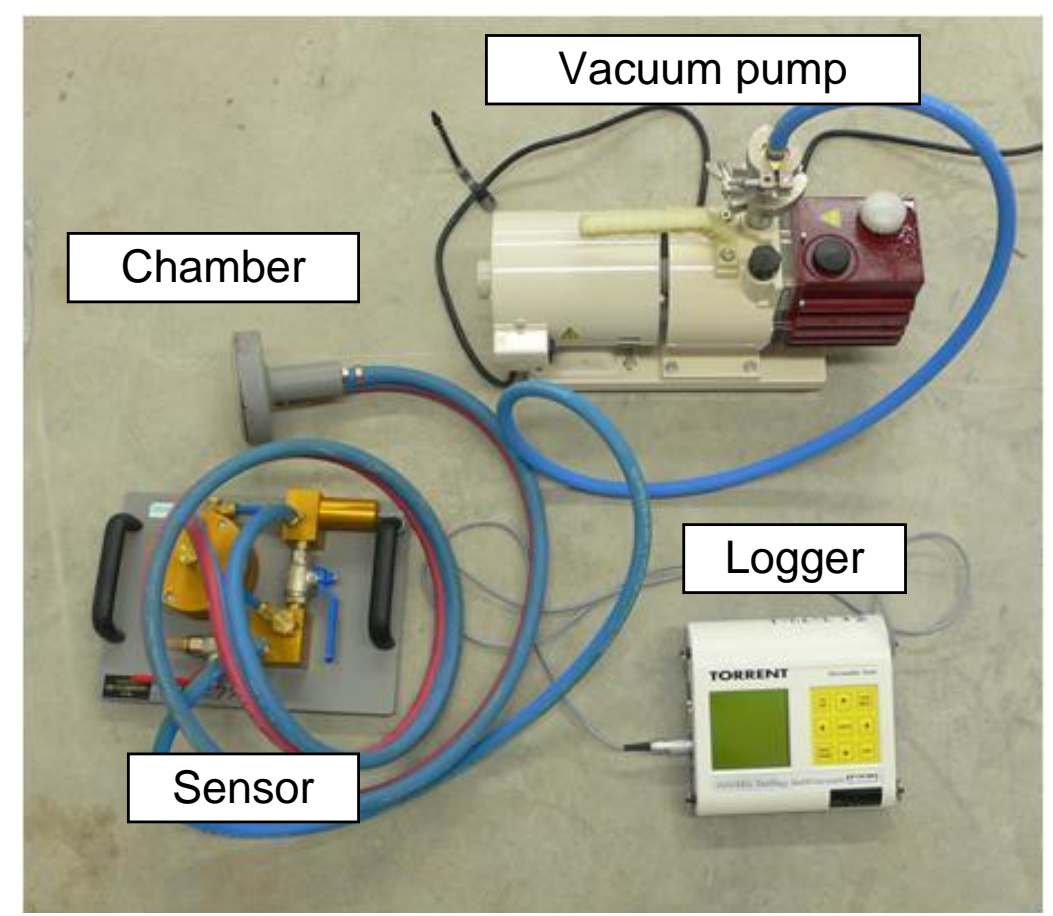


Figure 4. Conceptual diagram of the chamber and air flow.

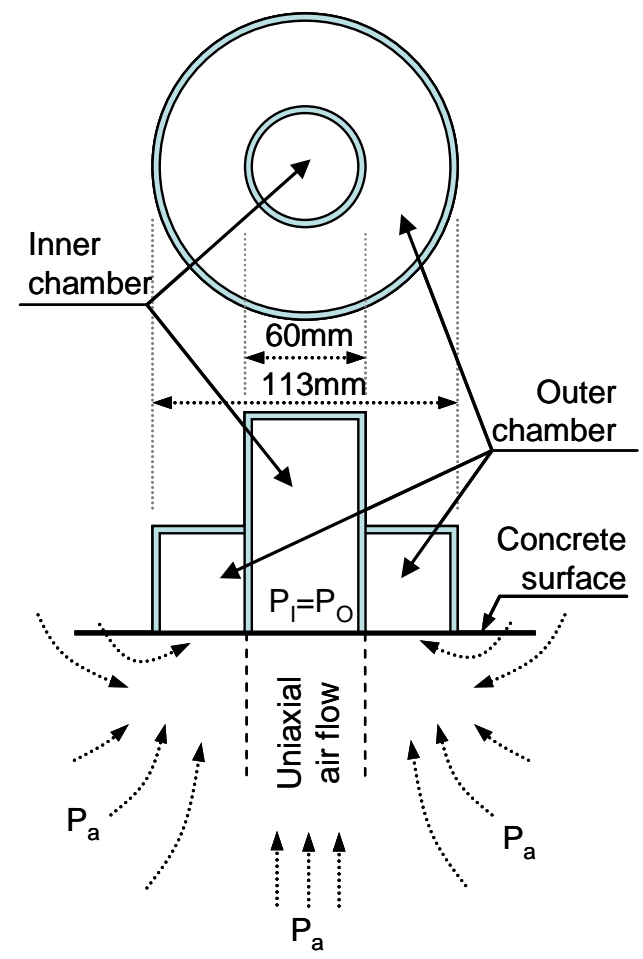

The air permeability coefficient can be directly influenced by the vertical crack due to bond cracking along rebar. In addition, this study suggests that losing concrete matrix between the surface and rebar because of tensile loading can also influence the air permeability coefficient. The air permeability coefficient had different values depending on the timing of the measurement, such as during loaded and unloaded conditions. As expected, the air permeability coefficient during loading was higher than that of the unloaded condition, there being about a 10\% difference, as shown in Figure 5. Actually, the air permeability coefficient during loading was more appropriate. Measuring the air permeability was done during unloaded conditions as well.

Ten measurement points (A to J) were selected along the rebar, as shown in Figure 6. Measurements were taken three times: before and just after loading and after recuring (autogenous healing). Each air permeability coefficient was compared to evaluate the damage and recovery effect.

Figure 5. Difference in the air permeability coefficient between loading and unloaded condition.
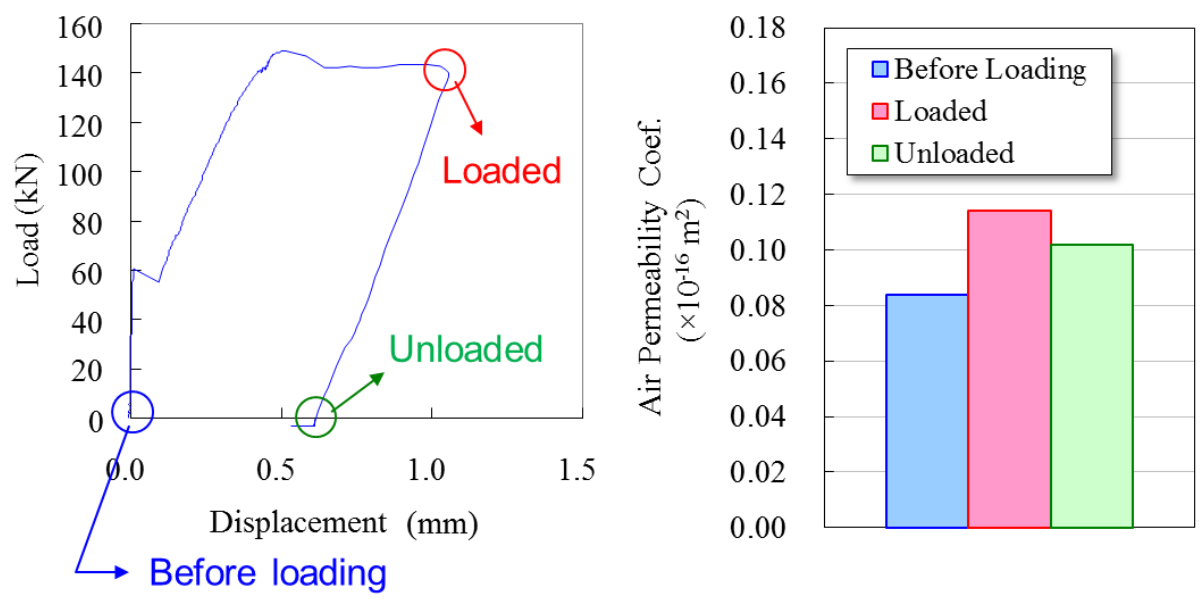
Figure 6. Measurement points in the air permeability test.

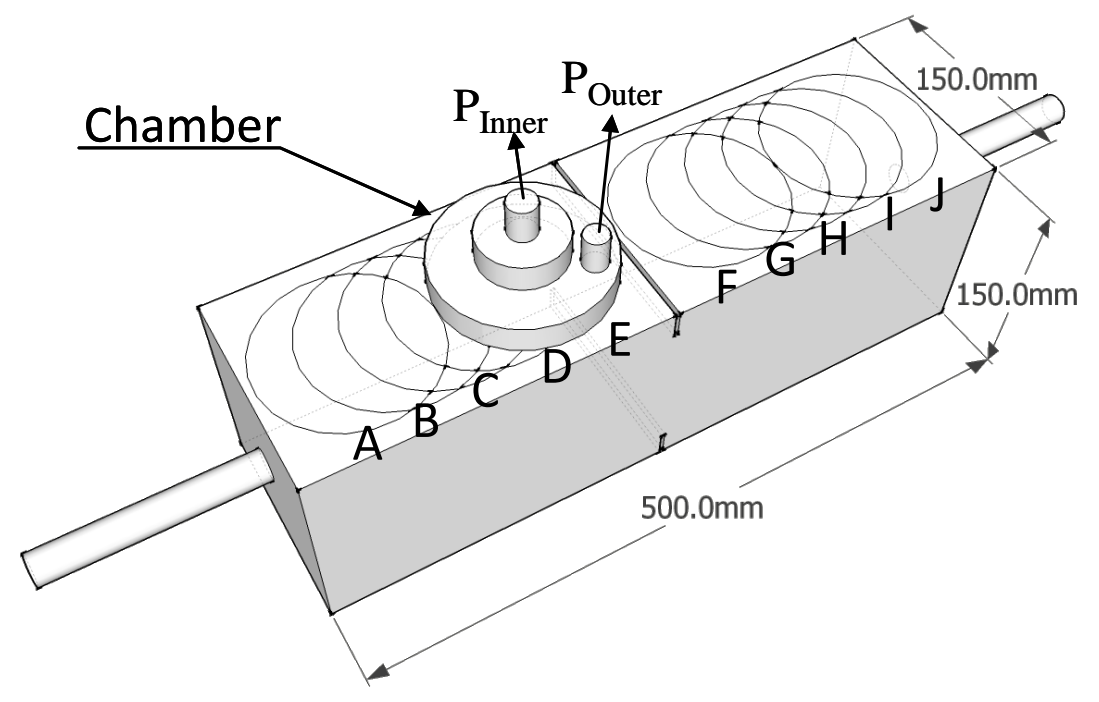

\subsection{Crack Pattern Observation}

The crack pattern was observed to evaluate the healing effect. The specimen size used was the same as the specimen shown in Figure 6, but the rebar was modified. Slits for ink injection were made on both sides of the rebar, as shown in Figure 7, based on previous research [11]. Slits were cut by a grinder, and were filled with styrofoam to prevent them from being filled by cement paste. Styrofoam was removed before ink injection. Red ink was injected into the slits, and the specimen was split in half using a concrete cutter.

During tensile loading, the peak loads of specimens containing rebar with slits were slightly lower than the normal specimen in air permeability test, and the residual displacement was also different. However, the difference in loads was about $5 \%$ and the unloading point was almost the same.

Figure 7. Slits in rebar for ink injection.
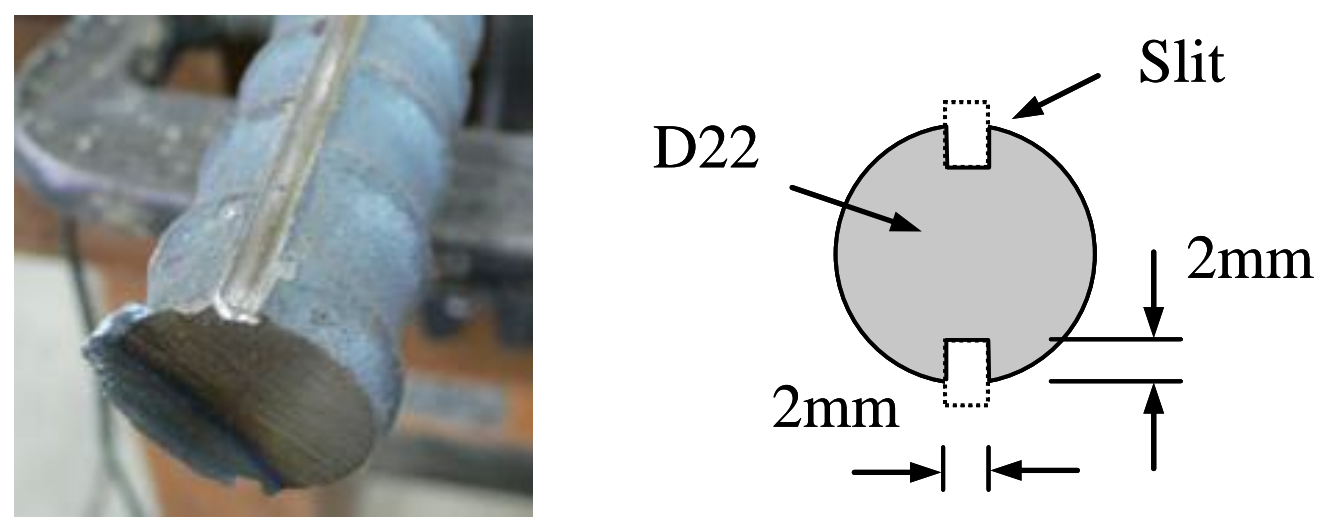

\subsection{Procedures}

All specimens were demoulded after $24 \mathrm{~h}$ after the concrete was cast, and cured in $20{ }^{\circ} \mathrm{C}$ water. Three specimens were prepared for the air permeability test in each series. Tensile loading was performed after twenty-eight days. Before and after the tensile loading, the air permeability coefficient was measured after 3-5 h natural drying to prevent the effects of moisture. Different recuring 
conditions were applied to each series after tensile loading. Air recuring refers to specimens recurred in a $20{ }^{\circ} \mathrm{C}$ curing room with are lative humidity(RH) of $70 \%-80 \%$, and one specimen was tested under this condition. On the other hand, water recuring refers to specimens recurred in $20{ }^{\circ} \mathrm{C}$ water located in a curing room. The remaining two specimens were tested in these conditions. Both recuring methods remained stable. By comparing the air permeability coefficient after recuring in air and water, more appropriate circumstances for autogenous healing could be investigated. Another three specimens were prepared for crack pattern observation. Crack patterns were first observed just after the tensile loading. The final two specimens recured after the tensile loading in air and water respectively. After recuring, the effect of autogenous healing was investigated through crack pattern observation. Figure 8 shows the outline of the experimental procedures.

Figure 8. Experimental procedures.
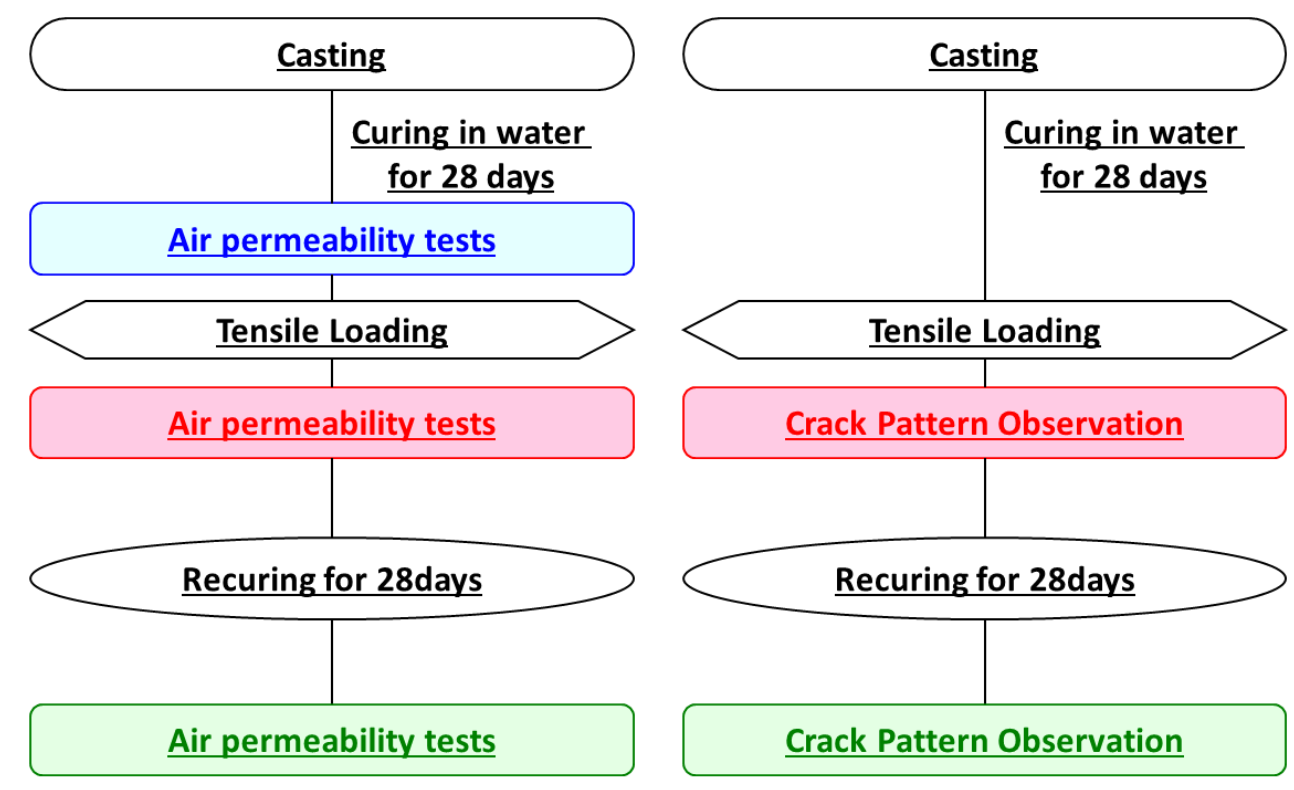

\section{Experimental Result}

\subsection{Results of the Air Permeability Test}

Figure 9 shows the air permeability coefficients of each normal concrete specimen before the tensile loading, after tensile loading, and after recuring. Air permeability coefficients of all specimens before the tensile loading were extremely similar near $0.1 \times 10^{-16} \mathrm{~m}^{2}$. After the tensile loading, air permeability coefficients became larger, and a relatively significant change was observed at $\mathrm{D}-\mathrm{G}$. This seemed to be influenced by the main crack caused by notches. After recuring, air permeability coefficients showed different aspects depending on the recuring condition. The air permeability coefficient of the specimen recured in water became smaller than that just after loading. It seems that recovery of micro cracks along rebar occurred during water recuring. However, there was no recovery trend in the specimen recured in air. 
Figure 9. Normal concrete air permeability test results. (a) Recuring in air; (b) Recuring in water-Specimen No.1; (c) Recuring in water-Specimen No.2.
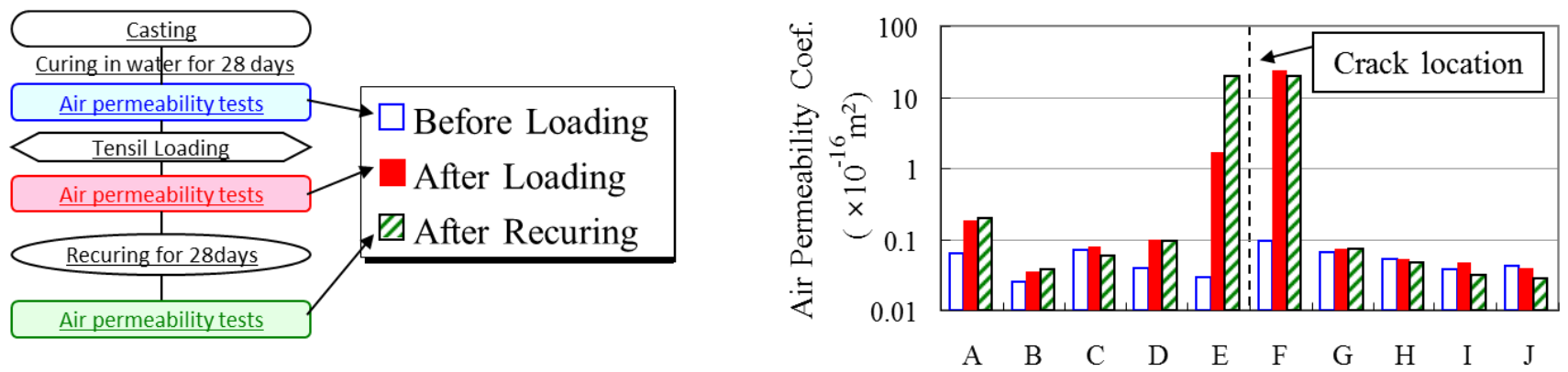

(a)

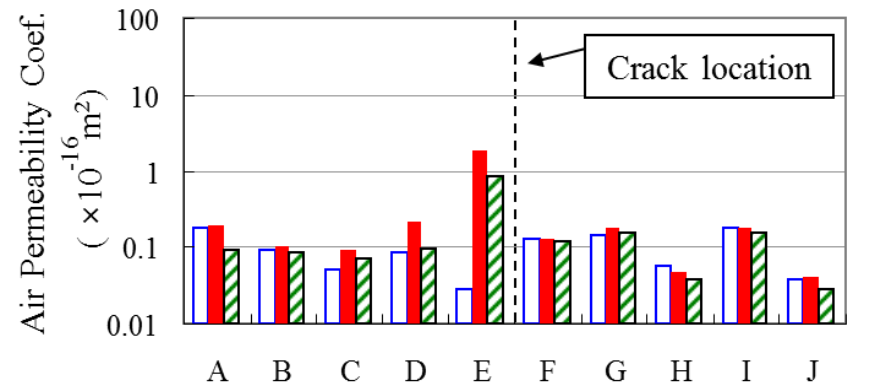

(b)

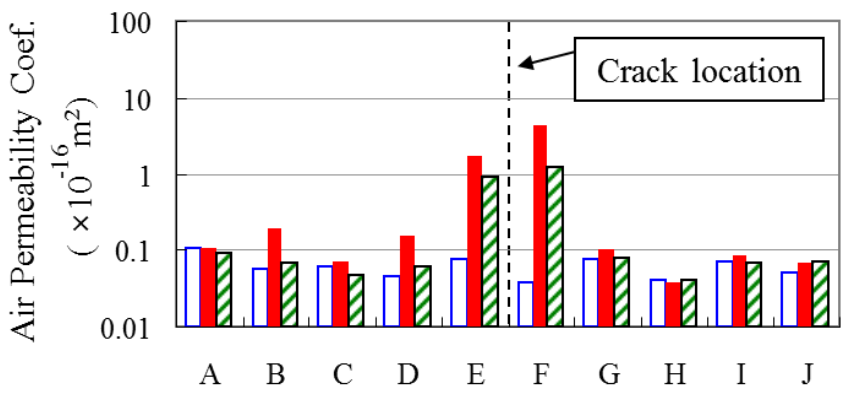

(c)

Figure 10 shows the results of the fly ash concrete specimen. The average air permeability coefficient was a little smaller than the normal concrete specimens. However, both specimens were generally the same, and an insignificant difference was observed.

Figure 10. Fly ash concrete air permeability test results. (a) Recuring in air; (b) Recuring in water-Spceimen No.1; (c) Recuring in water-Specimen No.2.
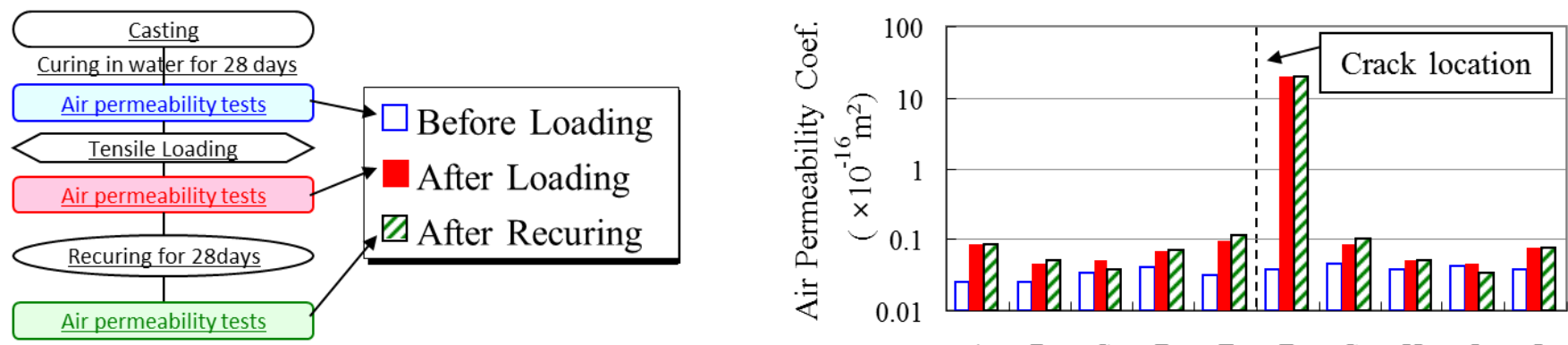

(a)

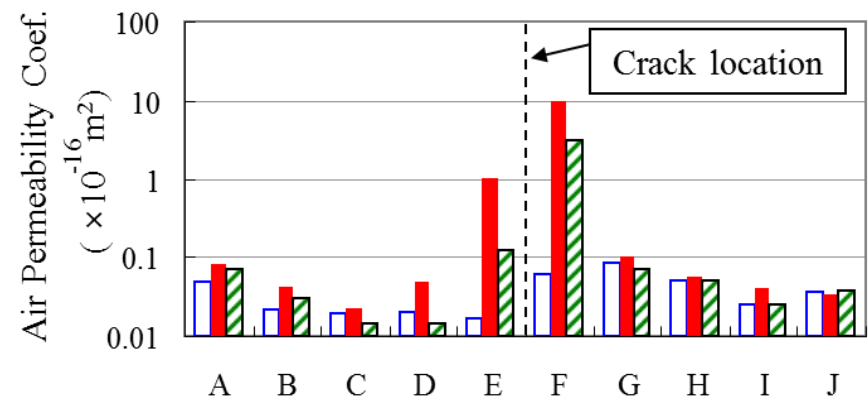

(b)

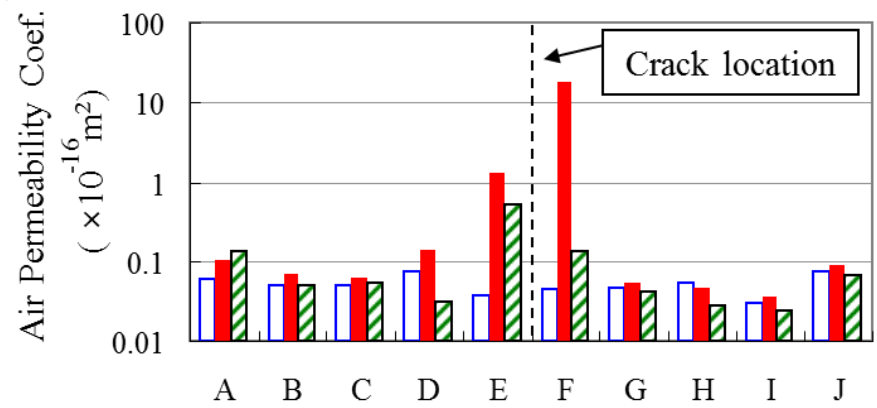

(c) 


\subsection{Results of Crack Pattern Observation}

The recuring effect was visually elucidated by crack pattern observation. Figure 11 shows the dyed crack pattern of each specimen. After tensile loading, micro bond cracks less than $2 \mathrm{~mm}$ long were observed near the rebar. Regardless of concrete type, a few cracks were observed after water recuring. It seems that generated products due to autogenous healing filled the micro cracks, and also influenced the air permeability coefficient. However, the observed crack pattern in specimens recured in air was similar to that just after the tensile loading. This means that autogenous healing during air recuring was not as significant as healing during water recuring.

Although air permeability coefficients showed lower values in fly ash concrete than normal concrete, it is difficult to find a significant difference in the crack patterns between these two types. It seems that the air permeability coefficient is more sensitive than can be detected by observation using the naked eye.

Figure 11. Observed crack patterns.

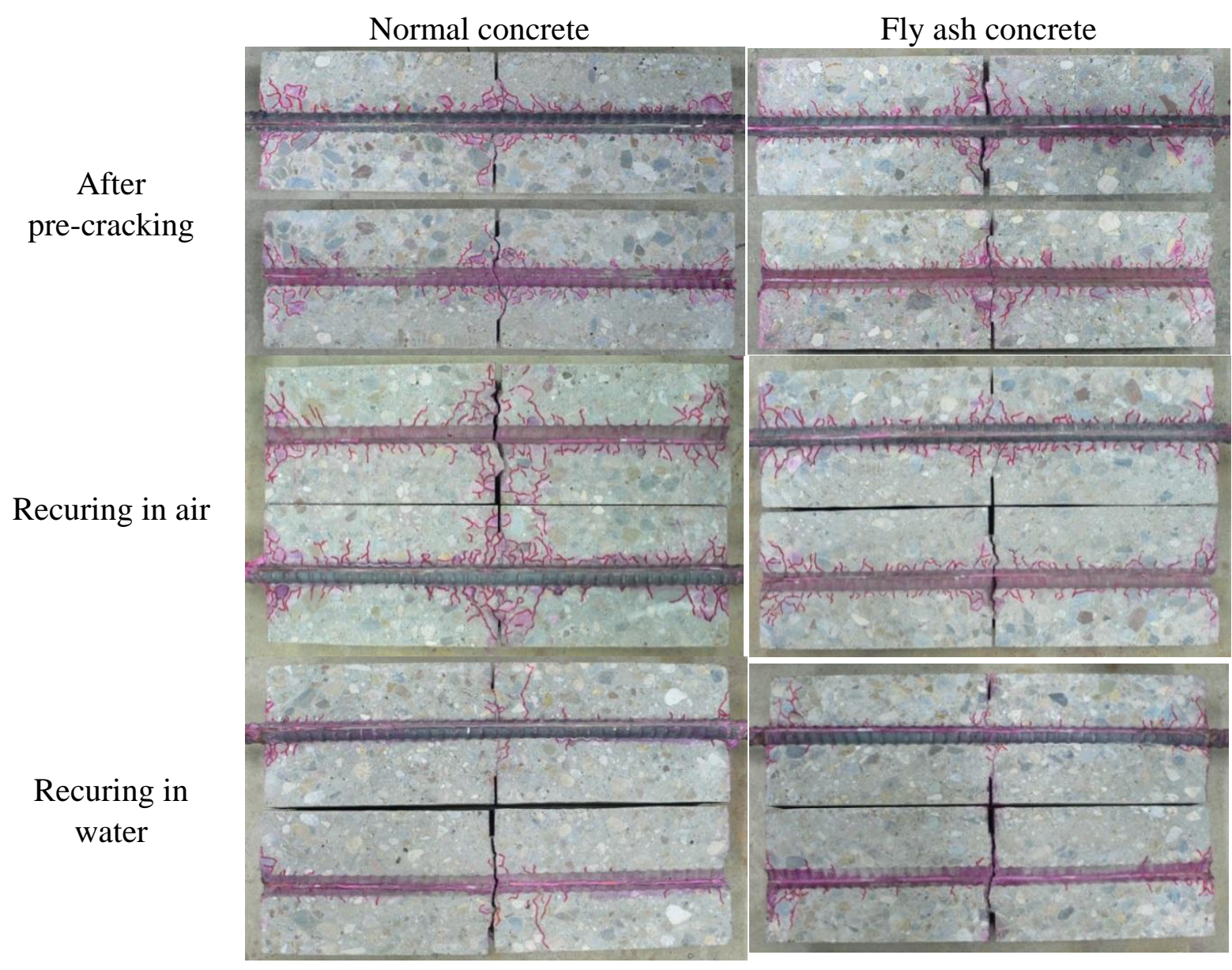

\section{Conclusions}

In this study, the autogenous healing ability of bond cracks along rebar was experimentally evaluated using the air permeability coefficient and crack pattern observation. The following conclusions are made: 
(1) The air permeability coefficient measured at the surface of a specimen was influenced by the bond crack along the rebar by tensile loading. The air permeability coefficient became larger as a result of damage done. Note that macro cracks were induced at the notched part, and micro cracks were not observed on the surface. The air permeability coefficient, however, became smaller because of water recuring. It seems that the rehydration products of cement filled the micro bond cracks. In this study the recuring period was twenty-eight days, and more significant recovery can be assumed with longer recuring period.

(2) Bond crack recovery was investigated by observing crack patterns just after tensile loading, as well as after recuring. A little crack was observed in the specimens that underwent water recuring. On the other hand, crack patterns of the specimen which underwent air recuring were almost the same as those just after tensile loading. The results of the air permeability test indicated that recuring in water was more conducive to autogenous healing.

(3) The adopted curing condition such as water curing might be difficult to apply to existing structures, and further research includes moisture conditions and its criteria should be investigated.

\section{Acknowledgments}

The author of this paper gratefully acknowledges that, the Ministry of Education, Culture, Sports, Science and Technology (Monbukagakusho) in Japan. And the previous researches in the technical report of Japan Concrete Institute is based on this study [12].

\section{Author Contribution}

The author express my thank to many Japanese student for helping the experiment, and discussions with Hikaru Nakamura and Shinichi Igarashi have been particularly helpful with autogenous healing effect.

\section{Conflicts of Interest}

The authors declare no conflict of interest.

\section{References}

1. Goto, Y. Cracks formed in concrete around deformed tensioned bars. ACI Mater. J. 1996, 68, 244-251.

2. Cook, J.; Gordon, J.E.; Evans, C.C.; Marsh, D.M. A mechanism for the control of crack propagation in all brittle systems. Proc. R. Soc. Lond. A 1964, 282, 508-520.

3. Li, V.C.; Stang, H.; Krenchel, H. Micromechanics of crack bridging in fibre-reinforced concrete. Mater. Struct. 1993, 26, 486-494.

4. Stang, H.; Li, V.C.; Krenchel, H. Design and structural applications of stress-crack width relations in fibre reinforced concrete. Mater. Struct. 1995, 28, 210-219.

5. Lauer, K.R. Autogenous Healing of Cement Paste. ACI J. Proc. 1956, 52, 1083-1097.

6. Van Breugel, K. Self-healing en vloeistofdichtheid. Cement 2003, 7, 85-89. (in German) 
7. Edvardsen, C. Wasserdurchläassigkeit und Selbstheilung von Trenrissen in Beton (Water Permeability and Autogenous Healing of Cracks in Concrete). Ph.D. Thesis, Institute of Building Materials Research, University of Technology, Berlin, Germany, 1994.

8. Termkhajornkit, P.; Nawa, T.; Kurumisawa, K. Effect of water curing conditions on the hydration degree and compressive strengths of fly ash-cement paste. Cem. Concr. Compos. 2006, 28, 781-789.

9. Termkhajornkit, P.; Nawa, T.; Yamashiro, Y.; Saito, T. Self-healing ability of fly ash-cement systems. Cem. Concr. Compos. 2009, 31, 195-203.

10. Torrent, R. A two-chamber vacuum cell for measuring the coefficient of permeability to air of the concrete cover on site. Mater. Struct. 1992, 25, 358-365.

11. Maruyama, I. Micro-Cracking around Deformed Reinforcing Bar in Ultra High-Strength Reinforced Concrete Members. J. Struct. Constr. Eng. 2007, 617, 1-7.

12. Igarashi, S.; Kunieda, M.; Hishiwaki, T. Research activity of JCI technical committee TC-075B: Autogenous healing in cementitious materials. In Proceedings of the 4th International Conference on Construction Materials: Performance, Innovations and Structural Implications, Nagoya, Japan, 27 June 2009.

(C) 2014 by the authors; licensee MDPI, Basel, Switzerland. This article is an open access article distributed under the terms and conditions of the Creative Commons Attribution license (http://creativecommons.org/licenses/by/3.0/). 